\title{
Improving Internet Communication Efficiency Using Ranking Promotion Tools
}

\author{
Valeriy Nikishkin
}

Marketing department, Plekhanov Russian University of Economics, Stremyanny per. 36, 117997, Moscow, Russian Federation

Email: valeriynik@yandex.ru

Tatyana Voronova

HRTaSI faculty, Plekhanov Russian University of Economics, Stremyanny per. 36, 117997, Moscow, Russian Federation

Email: info@rea.ru

\section{Maria Tverdokhlebova}

Marketing department, Plekhanov Russian University of Economics, Stremyanny per. 36, 117997, Moscow, Russian Federation

Email: tverdohlebova@yandex.ru

\section{Doi:10.5901/mjss.2015.v6n4s3p271}

\section{Abstract}

\begin{abstract}
Although the spread of internet in Russia started only in the early 2000s, nowadays it has more than 75 millions of users. International companies working on the Russian market, extensively use it for communicating with the Russian target audiences. The efficient internet promotion of sales and services of the companies for the consumer market (B2C) is high enough. At the same time, the issue of the efficient internet-communications for production enterprises (B2B) has been investigated much less, though, this concept is absolutely important today. This paper describes formation of complex-valued system to promote services of the logistics companies in the Russian Internet (called "Runet") on the basis of the internet communication tools. The proposed solutions are demonstrated on the example of Russian Company Prime Logistics LLC, and appear to be useful for foreign logistic enterprises which entered the Russian market, since "Runet" has its own peculiarities. We conducted structured expert polls with 20 selected experts, collected and reviewed of search inquiries in Russian search databases. Our findings can be used for selecting the most effective promotional tools in achievement of different communication goals, construction the sequence of necessary instruments and planning communication budget. Elaborated recommendations can be introduced in the work of the enterprises operating at the $B 2 B$ market in the field of logistics. The timeliness is conditional upon the constant increase of the internet importance as a communication medium for the representatives of inside and outside audience of the companies at the B2B market.
\end{abstract}

Keywords: market, logistics, international shipment, internet communications, corporate site, search engines promotion, digital advertising, public relations, Russian Federation

\section{Introduction}

At the start of the "digital media" age, arrangements and structure of marketing communication have undergone changes due to the development of the internet technologies (see Sukhova, 2009; or Matušková and Strielkowski, 2014). The interactivity of the promotion tools becomes an important feature of the modern age. Nowadays, in most cases the consumer selects the desired search engine by herself or himself and choses which company to perform communication with. It makes marketing experts to overview the approach to the complex-valued marketing communication considering their interactive features and dynamism (Koudelková et al., 2015). As a result, new tools of communication interaction are appearing on the internet, and the existing ones experience sufficient technological changes (see Cabelkova et al., 2015).

Against a backdrop of the quantity of the investigations devoted to the utilization efficiency of the tools of the internet communication, the issue of complex-valued promotion on the internet considering the importance in impact of that or another tool for the companies operating at the specific market, it is not disclosed to the full (see e.g. Tejkalová 
and Strielkowski, 2015). The present investigation has been devoted to the elaboration of the marked issue for the companies functioning at B2B market in the sphere of logistics. A proposal on availability of searching demand for the services of the logistic companies initiated by the users in the network has become the first hypotheses verified as the part of the research. The following proposal has become the second hypothesis: various tools of the marketing communication in the network have different impact level on the achievements of different types of the communication tasks. a) image b) informational. The proposed structure of the investigation can be applied for the tools arrangement of on-line communication applicable to any market. Gained results in the course of the investigation can be used by the companies in the sphere of international shipment.

Our research objectives directly bear to larger tasks of the collective sphere - efficiency upgrading of the Internet marketing for different business structures. In particular, it concerns on-line communication. The issues on the Internet communication efficiency raise are concerned in the works of many authors, while the issues of complex approach to the marketing communication had been regarded separately. In Russia, the rating of tools significance in the internet communication aiming at achieving different types of communication tasks applicably to the enterprises of the logistics profile has not yet been elaborated.

The proposed scheme of investigation to the authors, including desktop research and expert structured poll, will allow confirming the proposed hypothesis and point out the most important communication tools for the market under the research and can be used for the elaboration of the complex-valued promotion of the logistics companies through the internet medium.

\section{Literature Review}

Most of the internet marketing research and communication focuses on content analysis of internet websites that employs the traditional marketing mix comprised of four elements (product, price, promotion, and place).

Rowley (2001) demonstrates that the internet demands a significant review of approaches to marketing communications at all levels. The way in which marketing communication is integrated with business operations makes it difficult to continue to view marketing communications as a limited activity. The level of integration of marketing communications depends on the stage of development of e-commerce. At the tactical level, channel, message and audience characteristics have implications for attracting attention, cultivating awareness, and assessing the impact of communications and promotional activities.

Lagrosen (2005) describes how traditional service companies use the internet in their marketing communication and what effect the internet has had on their use of other marketing communication channels. His findings demonstrate that small or decentralised companies use the personalised relationship communication strategy, while the larger companies use either the mass relationship communication strategy or the mass transaction communication strategy.

Berthon et al. (1996) or Ngai (2003) show that an increasing volume of internet marketing research has been conducted in a diverse range of areas and the significance of e-commerce is gaining importance and will even increase more in the future. However, more recently a more consumer-oriented approach to internet marketing communication has found its wider use and is now applied more frequently in practice.

For instance, Filo and Funk (2005) demonstrate a new approach to internet marketing communication that allows coordinating venue-based consumer experience with virtual content provided on websites to capitalize on features of the product demanded by the consumers. Their results show some congruence between the product features identified by event attendees and the website communication.

Castronovo and Huang (2012) provide an overview of the literature landscape surrounding word-of-mouth (WOM) marketing, alternative marketing communications, and social media as viable components of integrated marketing communications.

Shih et al. (2013) develop a search engine optimization (SEO) mechanism that can be used for improving the ranking in the search engine results for social networking sites that are included in the internet marketing strategy. The rankings are obtained from two online search engines (Google and Yahoo) and are evaluated in efforts to explore a better strategy to ensure higher rankings.

Moreover, there are new ways and approaches to internet marketing communication, such as the so-called "meaningful marketing" described for example by Pulligada et al. (2014) who define it as the "non-interruptive, nonpersuasive marketing communication that provides utility to the consumer independent of consumption of the brand's product or service". 


\section{Research Methods}

The structure of the task has suggested the sequential conduction of several stages of the investigation which is similar to those used in comprehensive analytical modelling (see e.g Strielkowski, 2014). Primarily, an analysis of search queries had been conducted, aimed at hypothesis confirmation on presence the search demand on the companies' services in the internet initiated by the users - e.g. international shipment. For this purpose, analytical service of Yandex - Wordstat Yandex was employed. Yandex is one of the largest internet companies in Europe, operating Russia's most popular search engine and its most visited website. According to Livelnternet, as of December 2014, it generated 59.3\% of all search traffic in Russia. It also operates in Ukraine, Kazakhstan, Belarus and Turkey (Savenkov et al., 2011).

It is designed for the evaluation of the visitors' interest to specific Internet topics and is usually applied in order to select the key words by the advertising spenders of the Direct Yandex (Yandex analog of Google AdWords) system. The service Wordstat Yandex contains detailed statistics of queries in Yandex for several months and provides with the forecast for the nearest period. Descriptive research by means of structured expert poll performance was the second stage. The poll was conducted in a remote mode by means of filling in the survey assisted by Google Docs (Roberts, 2013). The experts were invited to participate via e-mail.

The following features such as post, term of service and place of work are considered in the capacity of the basic parameters in selection of the experts. As the result, the marketing managements, senior managers and directors of the logistics companies were selected for the investigation as well as university professors and lecturers specializing in online marketing. The total number of the participants comprised 20 persons. Training on conducting a telephone interview was carried out with each expert prior to getting the survey in the course of which the researches explained the goals and objectives of the poll to the participants as well as the technology of the survey fill in.

The researches applied the survey containing 42 closed questions. Each question was formulated in the form of detailed rating balanced scale with the number of the categories being equal to five (including neutral category). The experts were asked to evaluate 21 tools of the marketing internet communication as to the extent of their influence upon the achievement of a) image b) informational goals of the logistics companies, by the categories from "no influence" to "much influence". The scale testing was performed beyond the principal poll upon three experts fitting in accordance with the performance goals.

\section{Results and Discussion}

Whereas the specific peculiarity of the B2B market is, first of all, to assume personal communication on the part of the companies proposing its goods and services, nowadays, many industrial customers initiate the search of necessary partners themselves using the internet - as the most efficient way on this purpose. While using the service Wordstat Yandex, the evaluation was performed on the search demand on the service of the company prime logistics initiated by the consumers, which renders logistics and transport services in accordance with the following directions:

- Intra-Russian and international consignments

- Customs clearance

- Customs clearance agents

- Logistics services

- Consultations on foreign economic activity (FEA)

The word combinations were selected by means of the service Wordstat, which were used by the users while searching information in the search engine Yandex relating to the subject matter above. The word combinations were selected out of them being potentially as transactional, i.e. typed in order to order similar services and not just aiming at information search. The number of the word combinations was 287, to which the total amount of the enquiries comprised 140657 per month. Therefore, more than $40 \%$ of the enquiries had upon five of the most requested key words by the users (see Table 1). 
Table 1: Evaluation of the potential quality of transaction enquiries on the subject of the logistics services in the Yandex search system (December 2014).

\begin{tabular}{|c|l|c|}
\hline No. & Key Word Combination & Number \\
\hline 1 & Motor Trucking & 13,938 \\
\hline 2 & Customs Clearance Agent & 13,228 \\
\hline 3 & Road Haulage & 12,810 \\
\hline 4 & Container Transportation & 10,305 \\
\hline 5 & Container Service & 10,098 \\
\hline$\ldots$ & & \\
\hline 284 & Cargo Customs Clearance from China, Cost & 33 \\
\hline 285 & Transportation of Container Unit & 32 \\
\hline 286 & Consultations on Fea & 32 \\
\hline 287 & Cost of Container Transportation 20 Tonnes & 29 \\
\hline & Total & 140657 \\
\hline
\end{tabular}

Source: Own results

According to data of the analysts of the Liveinternet Portal, the ratio of Yandex search engine comprised $53 \%$ in 2014 at the Russian marker of the search Internet services. Google is the second one as to the importance of the search engine in ratio of $34 \%$ (http://www.liveinternet.ru). In such a way, it is possible to calculate the total quantity of the enquiries on the basis of this ration as to two search engines, which will comprise 230889 per month. It confirms the hypothesis about the existence of scale enquiry initiated by the users concerning the logistics services in the internet and as a consequence of importance of Internet communication to attract these clients.

B2B market has the series of principal dissimilarities from the consumer market influencing sufficiently upon the use of the tools of the marketing communication in this sphere. A range of its peculiarities influences upon the difference of the marketing tools balance at B2B market, in particular the other model of decision making on purchase, high degree of buyers' competence, etc. In this regard, there are positions of communication tools in the traditional model of marketing communication as to its importance at the industrial and consumer markets. The personal sales for B2B market posses the first place, then sales stimulation, advertisement and only afterwards public relations and brand formation. However, the present rating taken out of the classic marketing literature (Ambler, 2003) can be named just as off-line tool of communication. Due to these features of the internet media, such as interaction and wide informational accessibility, represented balance of communication tools shall be apparently modified. Considering interactivity to be the essential difference of the Internet, i.e. the individual client's search of information necessary for him and release of this information on his enquiry, the balance of communication tools importance at B2B market in online mode is shifted aside, to more traditional for B2C. Conducted investigation has shown that search demand for logistics services in the internet initiated by the users exists and it is sufficient enough, i.e. the model of client's behaviour changes in the internet. The client also performs an active search in the Internet. Thus, the role of such tools as advertisement, public relations that increased promotion in the search engines gains the greater significance.

For further evaluation of the significance level of the communication tools, we propose to base upon the their classification not according to the technological characteristic but to the functional one in terms of solvable problems in the field of communication. In such a way, we define two groups of tools. The first group includes tools aimed at solving strategic tasks on formation of long-term emotional relations between the consumer and trade mark, i.e. image tasks. The second one possesses tools of communication solving informational tasks: for example, goods representation, sensitization about the brand, etc. Classification according to the mentioned characteristics shall be conducted for each separate project in the field of communication, as any of the tools in the individual cases can belong either to the first or the second group (Antipov, 2012). 
Table 2: Top list of communication tools directed on achieving image and information goals

\begin{tabular}{|c|c|c|}
\hline \multirow[b]{2}{*}{$\begin{array}{l}\text { Groups of communication } \\
\text { tools on their importance }\end{array}$} & \multicolumn{2}{|l|}{ Communication Tools } \\
\hline & $\begin{array}{l}\text { Enabling the achievement of } \\
\text { information goals }\end{array}$ & Enabling the achievement of image goals \\
\hline The most important tools & $\begin{array}{l}\text { 1. } \text { Corporate site; } \\
\text { 2. Promotion in search engines; } \\
\text { 3. Search text advertisement; } \\
\text { 4. E-mail newsletters }\end{array}$ & 5. Corporate site \\
\hline Important tools & & $\begin{array}{l}\text { - Loyalty programmes } \\
\text { - Customer support } \\
\text { - Track and management on reviews and comments at the external } \\
\text { online media (Mass Media, weblogs, social networks, etc.) } \\
\text { - Creation and maintenance of pages and groups at the social } \\
\text { - } \text { Petworks } \\
\text { - Text advertisement (context, article, etc.) }\end{array}$ \\
\hline $\begin{array}{l}\text { Tools of intermediate } \\
\text { importance }\end{array}$ & $\begin{array}{l}\text { 1. Banner advertising } \\
\text { 2. Creation and maintenance of } \\
\text { pages and groups at the social } \\
\text { networks } \\
\text { 3. Information layout in catalogues } \\
\text { 4. Information layout in other online } \\
\text { media }\end{array}$ & $\begin{array}{l}\text { - Promotion in search engines } \\
\text { - Press-centre } \\
\text { - Creation and maintenance of personal weblogs (corporate / } \\
\text { personal, of firms staff) } \\
\text { - Work with online journalists and bloggers - event management } \\
\text { - Press-releases mail out for publications online in Mass Media and } \\
\text { weblogs }\end{array}$ \\
\hline
\end{tabular}

Source: Own results

In virtue of conducted expert poll, the estimation five-grade scale is performed to the allocated tools of marketing communications due to the level of their impact upon the achievement of image and information targets at B2B market. The results were led to the average values (see Appendix A). By means of tools exclusion by receiving the estimate of lower satisfactory, we can separate three groups of communication tools: "The most important", "Important", and "Intermediate importance" in order to reach image and information goals of the company (Table 2).

Thus, only corporative site was named as the most important in order to achieve image goals, and other tools were distributed in the rest groups. The tools were separated irregularly on importance level to achieve the informational goals: four of them were marked as the most important and four were classified to the group of intermediate importance.

Not all tools possess the same importance in reaching a) image b) information goals. The obtained rating in a result of the investigation will allow allotting primarily those tools being more important in reaching the goals of the company. Furthermore, it is necessary to consider many interconnected tools and their complex-valued application to get the best result. In the course of further analysis, the tools have been considered falling into the groups "the most important" and "important" to reach image and information targets as well as their relations are marked with those tools with which they can cooperate in complex.

In order to achieve image and information goals availability of the corporate site of the company is of utmost importance. In order to achieve image goals at the site a section Press-centre containing information and contacts for the journalists and bloggers shall operate, client support shall be done in online mode and Loyalty programmes to be reflected. Tools of online calculation of order cost and delivery tracking will extremely important. It is necessary to have a form to subscribe for the company's news and proposals on the site for further work of e-mail newsletter.

Such a tool is closely connected with the corporate site in the capacity of promotion in the search engines. While elaborating it, it is important to mean the necessity of the site content optimization to the semantic hub (list of key words) for promotion in the search engines. Considering the peculiarities of the ranking algorithms of the search engines to be such that the content is given one of the dominate roles in defining the correspondence of the site to one or another enquiry, each three-four search enquiries on the site shall contain separate, relevant to them page.

The list of the key words is specified by the corresponding company staff together with seo-optimizer. In order to reach information goals, transaction enquiries are collated for image impact, the site is promoted on company's name, sphere of work, in some cases on the names of the competitive companies and their products.

For promotion, it is reasonable to pay attention to such search engines as Yandex and Google, as more than 80\% 
of the searches go through them [http://www.tns-global.ru/].

Text search advertisement (advertisement on the pages of the search engines) is efficiently working on the following media: Direct Yandex, or Google Adwords. In the capacity of the search words for text advertisement it is necessary to use word combinations from semantic row selected to promote in the search engines. For example, those words not receiving good positions in the search result, those words for which it is very difficult to make a separate appropriate page on the site or the most complicated ones for promotion, are highly competitive. For text advertisements, it is also necessary to match the most relevant pages of the corporate site for these enquiries the links will be referred from these announcements.

E-mail newsletters, as a tool of direct marketing, will be efficient in reminding about the work of the Company and notification about new services and actions conducted in the frames of Loyalty programmes. However, at B2B market in order to preserve positive image it is better not to apply "cold" newsletters, which can be conceived as spam, and to perform them according to earlier collected base of the site subscribers.

Loyalty programmes - is an instrument applied fundamentally in offline media for the present market, however, information about the programmes shall be reflected at the corporate site being usable as news hook for e-mail newsletter, social networks, and press-releases.

Customer support service shall operate on the corporate site, the user shall have an opportunity to ask a question to the operator online or send a request letter.

Tracking and work with feedbacks and comments is extremely important for image constituent of the marketing communications. The present consumer is much more convinced in trusting independent feedbacks rather than statements of the Company's representatives. This function can be an obligation of the work of press-service.

Nowadays, the following services can be named as the most famous and significant for the users on the feedbacks: site of feedbacks on goods and services, including at B2B market (http://irecommend.ru), site of feedbacks on goods and services, including at B2B market (http://otzovik.com/), site of feedbacks on companies and enterprises (http://www.spr.ru/), site of feedbacks on goods and services, including at B2B market (http://otzyvov.net/).

Creation and maintenance of pages and groups in the social networks is important to achieve image goals rather than informational ones. Primarily, these tools are applied for the organization of the additional pages containing information about a company, which can be demonstrated also in results of search engines outputting on the image enquires allowing to occupy some places in TOP-10 of the search engines at once. Secondarily, these mediums can be also used by the client's support service as many modern users get used and are comfortable to communicate in the social networks, where they have parallel access to different companies and persons.

Facebook can be marked as a medium to conduct work in the logistic company among the social networks (according to the priorities of the target auditory of the network) (http/lwww.facebook.ru), which is a popular social network among the specialists and executives, Vkontakte (http://vk.ru) - social network possessing more than $60 \%$ of the market of the social networks in Russia (http://www.tns-global.ru/), Linkedin (https://www.linkedin.com) - is a network of professional contacts.

Publication of news and releases of the company at the personal site is necessary for image support of the company as approval of that company is "alive", performs its work actively and updates information about its activity. Besides, this factor influence upon the indexation of the site by the search engines directly. Since the site is indexing at a rate proportional to frequency of its update. More seldom the changes are performed on the site, more seldom the site is visited by the search engines and update of the search positions takes place rarely.

In some cases the enterprises shall also effectually apply text article advert (besides search one), since it has a possibility to present more complete information about the problems at issue, to disclose specific subject in more details. Text advertisement also promotes the site rising in the results of search engines output in case if it contains the links to the corporate site.

The following tools are the least important for B2B market, but in some cases able to provide with positive results. For image effect:

- Creation and maintenance of personal weblogs (corporate / personal, of firm's staff) - similar work can be rendered positively in image organization, as in information open company, and can assist in work of the press-service, the back links from the weblog influence upon the position increase in issue of search engine.

- Event planning - this tools can be applied in the capacity of subsidiary one in organization of Loyalty programs, getting positive feedbacks towards the company.

- Press-releases mailout for the publications in online mass media and weblogs - is used for info media filling by data on the company, increase of its mentioning in the electronic mass media, correspondingly distribution in the search engines as well upon availability from the electronic articles of the backward references, influences upon the positions promotion in issue of the search engine.

For information effect: 
- Banner advertising - when using banner advertising with the link to the site, it is capable to take the client to more detailed information as well as affect indirectly on positions increase in the output of the search engine.

- Information layout in the catalogues and other mediums - directly besides the visitors coming from the catalogue, the back links to the site have a knock-on effect on the output of the search engine and directly affect if the text of the link coincides with one of the key word combinations. In such a manner, the Companies have to pay a particular attention to the tools in order to achieve the targets on efficient marketing communication at B2B market, which are marked in the items 1-8 and consider the possibility of supplementary work with the tools listed in Item 9.

\section{Conclusions}

Overall, the obtained results allow us to approach to the following conclusions: the availability of search demand for the services of logistics companies initiated by the consumers in the internet was confirmed, with the demand being sufficient. In such a way, the work on promotion in the internet is necessary for gain successes in the case of logistic enterprises.

Nowadays, marketing communication conducted in the internet is an obligatory attribute for any successful company at B2C and B2B market. It is closely connected with the increasing role to influence on the consumer, its active position in the search of information in the network, easier possibility of comparison among various suggestions and access to the feedback of other clients. When operating with the internet tools, it is necessary to understand clearly their role in reaching two principal communication goals: image and information. Various sets of tools run on each of them to different extents, which is necessary to be considered while defining the communication strategies of the firm.

Application of investigation results is expected at the enterprises rendering logistic and transport services, including of the prime logistics company. Application of the complex approach to the marketing internet communication is called for decreasing the general expenses of the company on promotion due to the receiving combined effect from the use of different tools of the marketing communication. Application of the elaborated methodology in the operational marketing planning will allow reaching the greater communication effect rather than at the use of separate tools in the internet promotion.

The tools in the internet medium as well as offline promotion cannot be considered as communication tools separately from each other as all of them are interconnected in direct or indirect way to influence on the work of other tools. Thus, for example, the search promotion is actively supported by the work in the social networks, publication of articles and press-releases, and it is impossible without preliminary fixed to it corporate site of the Company. In its turn, the corporate site actively interacts with the social networks, article advertisement, etc. The event planning is necessary for creation of the news grounds and support of the loyalty programs, which, in its turn, shall be reflected in the social networks and at the site of the firm as well. Thus, the work with separately taken tools of marketing communication on the Internet is often insufficient, which constitutes the limitations of our research.

The analysis of the potential demand on the services of the logistics company in the internet has demonstrated that the demand for it exists and it has a great value. The service market of the logistics company can be rather wide and the clients can be diverse. Their pool ranges from those in need of international shipment to those in need of consultations on FEA. And it is evident that attraction of the second group of the clients has also a great sense as the further tasks of the sales manager is its transference to other group of clients ordering not only consultations and also the very shipment services. In this connection, the communication tools must never be underestimated being traditionally regarded as more appropriate for B2C market - social networks, weblogs and email updates.

The proposed approach in promotion of the services of the logistics company in the internet takes into account the influence of each tool of the Internet communication upon the achievement of one of the goals - sensitization or formation of positive image - and shows in what way the tools interact between each other providing the integration effect. When it comes to the new pathways of research, calculation of economic benefit from using each of the communication tools and their arrangement according to their degree of impact and by to the expected economic benefit might be one of the best options. Our results can be used while promoting the new and existing companies in the internet, functioning at B2b market, including in the sphere of logistics and transport. Our methodology can also be expanded for the other spheres of B2B market.

\section{Acknowledgments}

The research was implemented at the Plekhanov Russian University of Economics by order for performance of the scientific researches on the subject: "Methodology of complex-valued promotion of the services of Logistic Company in the Internet medium". Customer: Prime Logistics LLC. The authors are thankful to company's chief, Mr. Kiselev for the opportunity to use the research material utilized in our paper. 


\section{References}

Ambler, T. (2003). Practical marketing / Translation from English under general editorship of Kapturetskyi , N. Saint Petersburg, SP.: Peter.

Antipov, K. (2012). Fundamentals of advertising. Moscow, M: Dashkov and Co.

Berthon, P., Pitt, L., \& Watson, R. T. (1996). Marketing communication and the world wide web. Business Horizons, 39(5), 24-32

Cabelkova, I., Strielkowski, W., \& Mirvald, M. (2015). Business influence on the mass media: a case study of 21 countries. Transformations in Business \& Economics, 14(1), $65-75$

Castronovo, C., \& Huang, L. (2012). Social media in an alternative marketing communication model. Journal of Marketing Development and Competitiveness, 6(1), 117-134

Filo, K., \& Funk, D. C. (2005). Congruence between attractive product features and virtual content delivery for internet marketing communication. Sport Marketing Quarterly, 14(2), 112-122

Koudelková, P., Strielkowski, W., \& Hejlova, D. (2015). Corruption and System Change in the Czech Republic: Firm-level Evidence. DANUBE: Law and Economics Review, 6(1), 25-46

Lagrosen, S. (2005). Effects of the internet on the marketing communication of service companies. Journal of Services Marketing, 19(2), 63-69

Matušková, A., \& Strielkowski, W. (2014). Technology Applications in Czech Presidential Elections of 2013: A Story of Social Networks. Mediterranean Journal of Social Sciences, 5(21), 419-424

Meerman Scott, D. (2013). The New Rules of Marketing \& PR: How to Use Social Media, Online Video, Mobile Applications, Blogs, News Releases, and Viral Marketing to Reach Buyers Directly (4th ed.) Wiley.

Ngai, E. W. (2003). Internet marketing research (1987-2000): a literature review and classification. European Journal of Marketing, 37(1/2), 24-49

Puligadda, S., DelVecchio, D., \& Gilbreath, B. (2014). 'Meaningful marketing': A process investigation of how consumers reward noninterruptive, nonpersuasive marketing communication. Journal of Marketing Communications, 20(5), 325-338

Roberts, S. L. (2013). The "Chalk Talk" 2.0: using Google Docs to improve the silent discussion in social studies. The Social Studies, 104(3), 130-136

Rowley, J. (2001). Remodelling marketing communications in an Internet environment. Internet Research, 11(3), 203-212

Savenkov, D., Braslavski, P., \& Lebedev, M. (2011). Search snippet evaluation at Yandex: lessons learned and future directions. In Multilingual and Multimodal Information Access Evaluation (pp. 14-25). Springer Berlin Heidelberg

Shih, B. Y., Chen, C. Y., \& Chen, Z. S. (2013). An empirical study of an internet marketing strategy for search engine optimization. Human Factors and Ergonomics in Manufacturing \& Service Industries, 23(6), 528-540

Strielkowski, W. (2014). Modelling the Impact of Infectious Diseases on Tourism. Applied Mathematical Sciences, 8(92), 4571-4577

Sukhova, S. (2009). 100\% Internet marketing. Saint Petersburg, SP.: Peter.

Tejkalová, A. N., \& Strielkowski, W. (2015). Media Coverage of Summer Paralympic Games (1992-2008): A Case Study of the Czech Republic. Mediterranean Journal of Social Sciences, 6(2), 578-582

\section{Appendix A}

Table 1A: Internet communication tools on reaching image and information goals at B2B market

\begin{tabular}{|c|c|c|c|}
\hline $\begin{array}{l}\text { Element of communication } \\
\text { complex }\end{array}$ & Internet communication tools & \begin{tabular}{|c|} 
Influence on reaching \\
information goals (from 1 \\
to 5 )
\end{tabular} & $\begin{array}{c}\text { Influence on reaching } \\
\text { image goals (from } 1 \\
\text { to } 5 \text { ) }\end{array}$ \\
\hline \multirow[t]{4}{*}{ Advertisement } & Banner advertising & 3 & 2 \\
\hline & Text advertisement (context, article, etc.) & 5 & 4 \\
\hline & Teaser advertisement & 1 & 1 \\
\hline & Covert advertising (product placement) & 1 & 2 \\
\hline \multirow[t]{10}{*}{ Public relations } & Publication of Company's news and releases at the personal site & 1 & 4 \\
\hline & Press-releases mail out for publications online in Mass Media and weblogs & 1 & 3 \\
\hline & Work with online journalists and bloggers - event management & 1 & 3 \\
\hline & Creation and maintenance of personal weblogs (corporate / personal, of firms staff) & 1 & 3 \\
\hline & Creation and maintenance of pages and groups at the social networks & 3 & 4 \\
\hline & $\begin{array}{l}\text { Tracking and work with feedbacks ad comments on other mediums (Mass Media, } \\
\text { weblogs, social networks, etc.) }\end{array}$ & 1 & 4 \\
\hline & Information layout in catalogues & 3 & 2 \\
\hline & Information layout in other online media & 3 & 2 \\
\hline & Customer support & 1 & 4 \\
\hline & Press-centre & 1 & 3 \\
\hline \multirow[t]{3}{*}{ Sales promotion } & Holding online promotion activities & 1 & 1 \\
\hline & Promotion website & 1 & 1 \\
\hline & Loyalty programmes & 1 & 4 \\
\hline \multirow[t]{2}{*}{ Direct-response marketing } & Corporate site & 5 & 5 \\
\hline & \begin{tabular}{|l|} 
Postal mailings \\
\end{tabular} & 5 & 2 \\
\hline \multirow[t]{2}{*}{ Other } & Promotion in search engines & 5 & 3 \\
\hline & Viral marketing & 1 & 1 \\
\hline
\end{tabular}

